\title{
Histomorphological diagnostic diffuculties in colon perforation
}

\author{
Yılmaz Baş ${ }^{1}$, Mustafa Şahin ${ }^{2}$ \\ ${ }^{1}$ Hitit Üniversitesi Tıp Fakültesi, Patoloji Anabilim Dalı, Çorum, Türkiye \\ ${ }^{2}$ Hitit Üniversitesi Erol Olçok Eğitim ve Araştırma Hastanesi, Tıbbi Biyokimya Bölümü, Çorum, Türkiye
}

\begin{abstract}
öz
$\mathrm{Bu}$ derlemede, kolon perforasyonu saptanan ve parsiyel/ total kolektomi uygulanan olgularda histomorfolojik tanı güçlükleri değerlendirildi. Patoloji pratiğinde klinik bilgiler dâhilinde kolon perforasyonunun histomorfolojik bulgularını rapor etmek güç olmamakla birlikte bazı vakalarda karakteristik bulguların olmayışı tanı güçlükleri doğurabilmektedir. Her ne kadar histolojik tanı için klinik bilgiler çoğu zaman yeterli olsa da, Crohn, amibik kolit ve intestinal Behçet hastalığı gibi vakalarda ayırıcı tanı güçlükleri patoloji pratiğinde yaşanmaktadır.
\end{abstract}

Anahtar Kelimeler: Kolon perforasyonu, Crohn, amibik kolit, intestinal Behçet

Sorumlu Yazar: Yılmaz Baş, Hitit Üniversitesi, Erol Olçok Eğitim ve Araştırma Hastanesi, Patoloji Bölümü, 19020, Çorum, Türkiye

E-posta: yilbas@yahoo.com

Geliş Tarihi: 22.02.2018

Kabul Tarihi: 14.03 .2018

\section{Giriş}

Kolon perforasyonu morbiditesi ve mortalitesi yüksek bir klinik problemdir. Klinik olarak acil tanı ve tedavi gerektirir (1). Perforasyon nedeni klinik ve histomorfolojik olarak belirsiz olan ve tanı güçlüğü doğuran vakalar nadir olmakla birlikte karşımıza ç1kabilmektedir. Bu gibi durumlarda cerrahi, patoloji, dermatoloji, romatoloji ve radyoloji gibi branşlar birbiriyle çok hızlı koordineli bir yaklaşım içine girmeli, tanı ve tedaviye yön vermelidir. Ön tanısı klinik olarak belirsiz olup acil laparoskopi ve cerrahi rezeksiyon gereken olguların bazılarında histopatolojik tanı güçlükleri de doğabilmektedir. Bu gibi durumlarda "patolog" tüm olası tanıları gözden geçirmeli ve kesin tanı verilemiyorsa bile tanılarını öncelik sırasına göre raporunda açıklamalıdır.

\section{ABSTRACT}

In this review, histomorphologic diagnostic difficulties were evaluated in cases that colon perforation was detected and partial/total colectomy was performed. Although it is not difficult to report histomorphologic findings of colon perforation within the clinical knowledge in the practice of pathology, the absence of characteristic findings in some cases may cause difficulties in diagnosis. Although clinical information is often sufficient for histological diagnosis, differential diagnosis difficulties are experienced in pathology practice, such as Crohn's, amebic colitis, and intestinal Behçet's diseases.

Keywords: Colon perforation, Crohn's, amebic colitis, intestinal Behçet's

Corresponding Author: Yılmaz Baş, Hitit University, Erol Olçok Training and Research Hospital 19020, Çorum, Turkey

E-mail: yilbas@yahoo.com

Received: 2018.02.22 Accepted: 2018.03.14

\section{KOLON PERFORASYON NEDENLERI}

Literatür kayitlarında, kolon perforasyon nedenleri arasında, spontan kolon perforasyonu $(1,2)$ fekal retansiyon ve kitle etkisi (2), "closed loop-kapalı ans" obstruksiyonu (2), adinamik ileus (2), inflamatuvar barsak hastalığı (2), amibiazis (2-4), enterokolit (2), barsak duvarının konjenital defekti $(2,5)$, vaskülitler $(2,6)$, Behçet hastalığ 1 (7), divertikülit (2), neoplazi ya da granülomun lokal nekrozu $(2,8)$, tüberküloz (Tbc) (8), volvulus (8) ve siklik nötropeni (2) sayılabilir. Singla ve ark. (8)'nın otuz beş nontravmatik kolon perforasyonu içeren çalışmasında en fazla perforasyon çekumda izlenmiştir. Perforasyon nedenleri; 13 vaka amibiazisli, 12 vaka nonspesifik ülserli, 5 vaka tüberkülozlu, 3 vaka adenokarsinom- 
lu, 1 vaka idiopatik intestinal gangrenli ve 1 vaka volvuluslu olarak tespit edilmiştir.

\section{HASTALIKLARA GÖRE KOLON HISTOMORFOLOJISI}

\section{Amipli dizanteride histomorfoloji}

Amipli dizanteri en sık çekum ve çıkan kolonu tutar. Sonra sirasiyla sigmoid, rektum ve apendiks tutulur (3). Amipli dizanteride hastalık primer olarak çekal bölgede yoğunlaştığında apandisit benzeri klinik belirti verir. Ĕger ülser ve perforasyonların yoğunlaştığ 1 sigmoid kolon primer tutulum yeri ise klinikte dizanterik bulgular ile karşılaşılır (9). Etken entamoeba enfeksiyonunun tanısı primer olarak dışkının mikroskobik incelenmesiyle konur (10). Fakat dışkı mikroskopisinin sensivitesi \%60'dan düşük ve spesifitesi \%10-50 arasındadır. ELISA yöntemi ile değerlendirildiğinde dışkıda antijen tesbitinin spesifite ve sensitivitesi \%95'in üzerindedir (11). Amibiazisde, kolonda 1-2 mm çapında küçük yüzeyel ülserler mukozada dağınık halde izlenir (9). Ayrıca nekroz ve geniş ülserler de izlenebilir. Daha çok ülserler çekumda yoğunlaşır $(3,9)$. Bir amip mukozal yüzde bir hücreye tutunduğunda ("sitoadheres") onu yok eder. Daha fazla amip daha fazla hücreye tutunduğunda ise nekroz başlar. İnflamatuvar reaksiyon polimorfonükleer lökositlerden oluşur. Mukoza nekrozu, submukozaya doğru ilerler ve ülserler hem aşağ1 doğru ve hem de laterale doğru genişleyerek tipik matara şeklini ("flask shape") alır (8-10). Ülserler, mukozayı, submukozayı ve muskularis proprianın iç kısmını, polimorfları, fibrin, mukus ve amipik trofozoit özelliklerine sahip sayısız tek hücreli organizmaları kapsar. Trofozoitler, makrofaj büyüklügüundedir ve bol miktarda eozinofilik PAS pozitif sitoplazmalı küçük, eksantrik, eozinofilik, yuvarlak çekirdeklere sahiptirler (8). Nadiren (\%5-10) muskuler ve serozal tabakayı penetre eden trofozoitler perforasyona neden olur $(10,12)$. İnvazif amibiazisin en sık cerrahi komplikasyonu kolon perforasyonudur (4). Ülser tabanı gri beyaz eksuda ile kaplıdır. Amibik kolitin tipik görüntüsü küçük ülserler ve arada kalan normal mukozadan oluşur (9). Bazı vakalarda mikroskobik perforasyonlar ve 2-3 cm çaplı yüzeyel, kanamalı, nekrotik materyal içeren ülserler izlenir (9). Ülserler çok sayıda olduğunda elonge ve kolon aksisin dikine doğrudur (9) ve geniş irregüler coğrafik patern oluşturur (10). Komplike olmayan amibiazisde ülserler kas tabakasının alt1na uzanmaz (9). Athie-Gutierrez ve ark. (4)'nın 122 vakalık bir çalışmalarında multiple kolon perforasyonu \%74 oranında bulunmuş ve sağ kolon \%90 ile

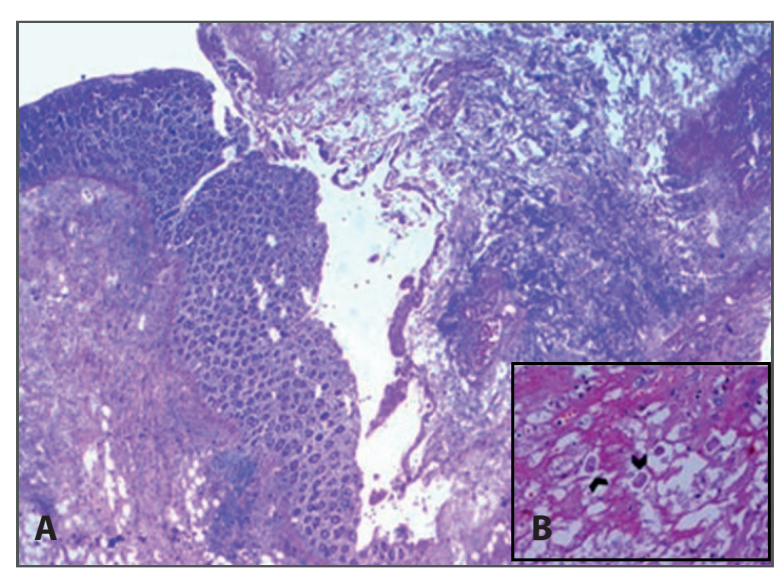

Resim 1A. Amibik kolite bağlı perforasyon alanı histolojik kesitinde trofozoid içeren "flask shaped" ülser dokusu (HE x4).1B (İç resim). Nekrotik materyal içinde amip trofozoitleri (HE x40) (8)

en sık etkilenen kısım olarak belirtilmiştir. Amibik kolit klinik yaklaşım olarak ülseratif kolit ve crohn hastalığını taklit eder (Resim 1- A, B) (8).

\section{Kolonik Crohn hastalığında histomorfoloji}

Crohn hastalığı \%40 oranında, ince barsak tutulumu olsun veya olmasin kolonu da tutar (12). Peng ve ark. (5) 1858 Crohn hastasını içeren bir çalışmasinda $157(\% 8,45)$ hastada gastrointestinal perforasyon nedeniyle cerrahi girişim uygulandığ1 belirtilmiştir. Crohn hastalarının \%1-3'ünde hastal1k seyrinde intestinal perforasyon görülebileceği belirtilmektedir (13). Makroskobik olarak atlayıcı (skip areas) lezyonların segmenter dağılımı ve sağ kolonu tercih etmesi iki önemli tanısal görünümdür (12). Crohn hastalığında kolonik segment daha rijit ve dar $(12,14)$ olup ülserler (fissürler) ise daha çok birbiriyle devam etmeyen, lineer-longitudinal, serpinjinöz, olmaya meyilli $(7,12,15)$, kaldırım taş1 benzeri (cobblestone) görünümdedir $(12,15)$. Fissürler ve yüzey mukozanın ve duvar yapısının dolgun görünümü morfolojide izlenir ve fistül en sik görülen komplikasyon olarak izlenir (12). Mikroskobik olarak nonkazeifiye sarkoid benzeri epiteloid granülomlar, fissürler (\%40-60 hastada tespit edilir) ve transmural tutulum kolonik Crohn'un tipik üç bulgusudur $(12,15)$. Crohn hastalığında vaskülit karakteristik bir bulgu değildir (6). Histolojik olarak normal mukoza tarafından çevrilmiş inflamatuvar hücrelerin iyi sınırlı bir odağı Crohn hastalığında özellikle görülür. Mukoza ve submukozada inflamasyon orantısız dağılım gösterir (12). Perianal hastalık ve fistül Behçet hastalığında çok nadir izlenir (6). Amibiazis, inflamatuvar barsak hastalığı üzerine eklendiğinde şiddetli sonuçlar doğurabilir. Ülseratif kolitli 130 hastada ve Crohn hastalığı olan 30 hasta- 
da E. histolytica prevalansını araştıran Türkiye>den bir çalışma, hastaların sırasıyla $\% 10$ ve $\% 3,3$ 'ünde trofozoitlerin bulunduğunu ortaya koymuştur (16).

\section{Kolonik Behçet hastalığında histomorfoloji}

Kronik, inflamatuvar, multisistemik ve vaskülitik olarak nitelendirilen Behçet'te hastaların \%10-50'sinde gastrointestinal sistem tutulur $(6,17)$. Bu hastalarda ileoçekal bölge tutulumu yaklaşık \%75'dir (6). Vakaların \%1'inden daha azında ülseratif değişiklikler görülür (17). İntestinal ülserler, aftöz ya da derin ve zımba deliğine benzer ("punched-out") yuvarlak ve oval görünümdedir $(7,15)$. Vakaların $\% 92$ 'sinde görülen intestinal ülserlere bağlı ağrı en sık klinik bulgudur (14). Longitudinal ülserler nadirdir $(7,15)$. İntestinal lezyonlar antimezenterik alan üzerinde düzensiz dağılımlıdır (7). Ülserasyonlar lokalize ve diffüz biçimde iki tipte oluşabilir (6). Ülserler penetrasyon, perforasyon ve kanamaya sebep olabilir $(14,17)$. Ülserli hastaların \%50'inde perforasyon ve penetrasyon oluşur (14). Cerrahi rezeksiyondan sonra rekürrens yaygındır (17). Lokalize lezyonlar ileoçekal bölgede oluşur, derindir ve serozal yüze penetredir $(7,14)$. Diffüz lezyonlar ise, kolonda daha yaygın, ayrı lokalizasyonlarda multipledir ve zımba deliğine benzer ülserlerdir (Resim 2,3, Yılmaz Baş Arşivi) $(17,18)$. Kasahara ve ark. (19) çalışmaların-

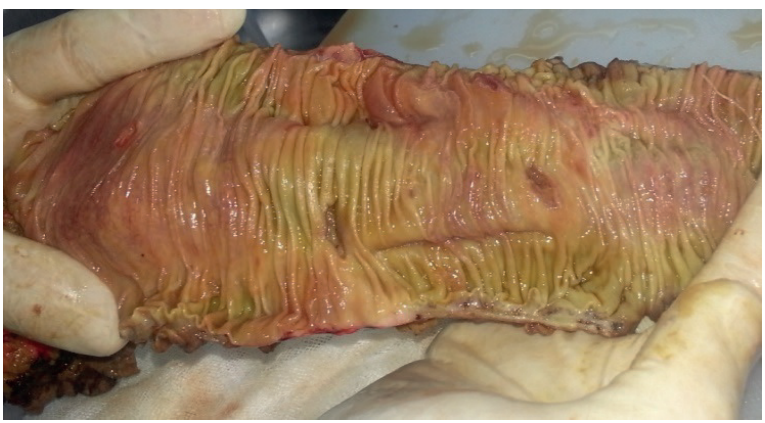

Resim 2. Kolonda oval keskin sınırlı ülsere perforasyon odakları (Yılmaz Baş arşivi)

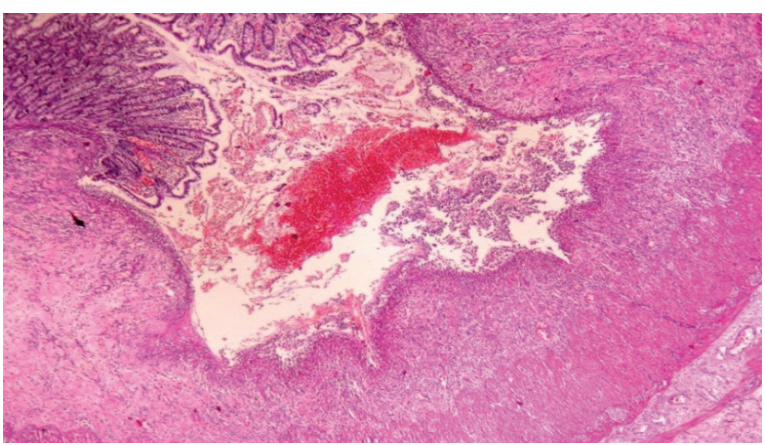

Resim 3. Behçet hastalığında derin ve zımba deliğine benzer ("punched-out") ülser (HE x10) (Yılmaz Baş arşivi)

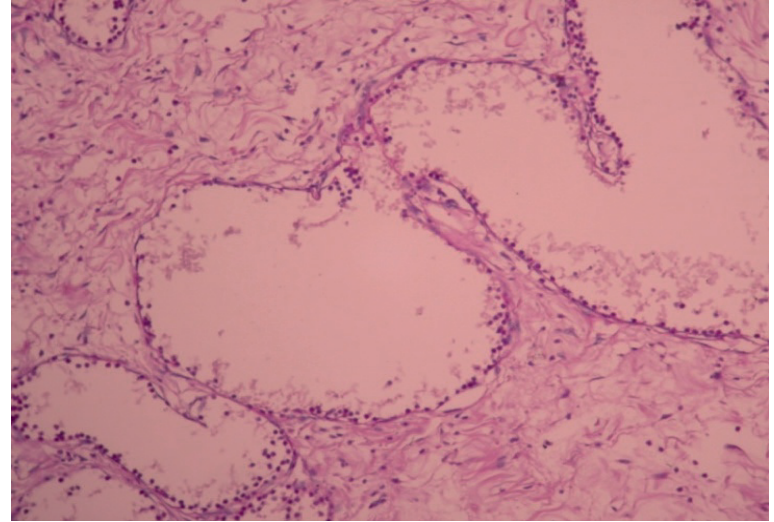

Resim 4. Kolon tutulumlu Behçet hastalığında venülit görünümü (Yılmaz Baş arşivi)

da enterik Behçet hastalığı olan vakaların \%73'ünde multipl ülserler, \%76'sında da siklıkla terminal ileum çevresinde yer alan lokalize ülserler tespit etmiştir. Behçet kolitinin diğer bir bulgusu submukozal venlerin lenfositik venülitidir (Resim 2,Yılmaz Baş Arşivi) $(6,12,15)$.

Rezeksiyon spesmenlerinde karakteristik vaskülit daha iyi değerlendirilir. Genellikle küçük çaplı damarlar, özellikle venüller tutulur ve intramural mononükleer hücreler ve nötrofilik infiltrasyon ile karakterizedir (Resim 4, Yılmaz Baş Arşivi). Bunun sonucunda fibrozis ve lüminal oklüzyon oluşur (6). Behçet hastalığının diğer histomorfolojik bulguları arasında lezyon dışı alanlarda normale yakın mukoza varlığ 1 ve lenfoid agregat ile granülomların bulunmayışı önemlidir $(6,7)$. Histomorfolojik bulgular Crohn hastalığına benzer özelliktedir (12). İleoçekal bölge en sık etkilenen kısım olması ile birlikte gastrointestinal sistemin herhangi bir kısmını etkilemeleri, relapsla seyreden sistemik bulguları, serum Anti-Saccharomyces cerevisiae antikor (ASCA) titrelerinin $\% 50$ yüksekliği ve anti-TNF tedaviye yanıtları Behçet hastalığı ve Crohn hastalığının benzer özellikleridir (6).

\section{Kollajenöz kolitte histomorfoloji}

Spontan perforasyon, kollajenöz kolitin (KK) seyrek ve ciddi bir komplikasyonudur (20). Perforasyon sonucu spontan peritonit vakaları da bildirilmiştir (21). KK'de kolon perforasyonu iki şekilde olabilir: 1) girişim ilişkili (kolonoskopi veya baryumlu lavman sirasında veya kısa süre sonra) ve 2) "spontan", diğer bir deyişle herhangi bir girişim ile ilişkisizdir. Gastroenterelog endoskopi esnasinda perforasyonu tanımlarken, "uzun, sı ğ, doğrusal veya serpijinöz mukozal ülser, genellikle" kolonun longitudinal ekseni boyunca uzanan ve her vakada birkaç çeşitli haustra kesitinde uzanan bir "çatlak" veya "yırtık" gibi 


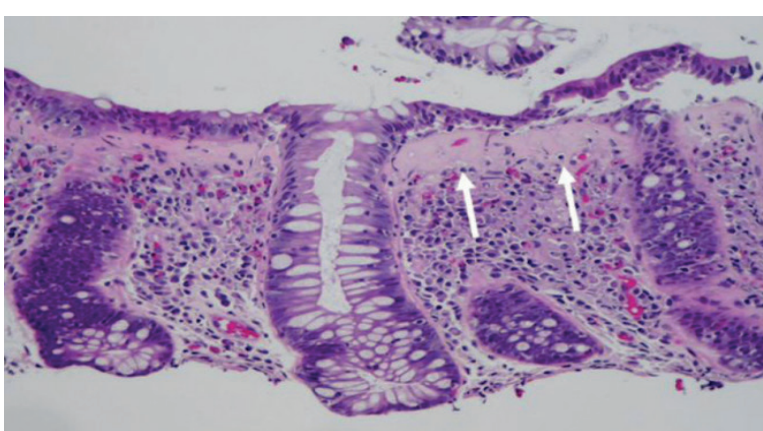

Resim 5. Subepiteliyal kollajen bandı (ok) (20).

göründüğünü belirtebilir (20). KK'da perforasyon en sık sağ kolonda görülür ve bunu transvers kolon izler. Nadiren sol kolonda da perforasyon görülür. Histolojik olarak KK'da epitelin lamina propriadan ayrılmasıyla birlikte subepitelyal kollajen bandının kalınlaşması ve mukozada lenfositik infiltratlarla karakterize görünüm mevcuttur (Resim 5) (20). KK'da inflamatuvar bağırsak hastalığının formlarıyla ilişki çok az kaydedilmiştir. Histolojik olarak kollajen depolar ile direkt olarak ilişkili olan yüzeysel mukozal dev hücrelerin seyrek olarak izlendiği ve bu vakaların bazılarının crohn hastalığına ilerleyebileceği veya ciddi ülseratif kolit haline dönüşebileceği belirtilmiş̧ir. Kolektomi gerektiren şiddetli ülseratif kolit ilerlemesini açıklayan bir raporda, rezeke edilen kolonda önceden varolan kollajen depolarının tamamen ortadan kalktığı da görülmüştür (21).

\section{Kolonik Tbc'de histomorfoloji}

İntestinal tbc'nin en s1k yerleştiği bölge ileoçekal bölgedir (22). Tüm abdominal tbc hastalarının \%1-15'inde intestinal perforasyon meydana geldiği tahmin edilmektedir (23). Çoğunlukla intestinal tbc vakaları üç morfolojik formda sınıflanır; ülseratif, hipertrofik ve ülserohipertrofik kombinasyon. Tbc'de perforasyon ciddi bir komplikasyondur ve yüksek mortalite ve morbidite sebebidir. En s1k görülen bulgu darlık olup, perforasyonlar ise genellikle tekdir ve striktür alanının yakınında görülür (22). İleoçekal tbc'yi crohn hastalığından ayırmak histolojik olarak gerçekten zordur ve klasik olarak intestinal tbc tanısı histoloji yanında seroloji ve kültür bulgusu gerektirir, fakat birçok çalışmada sadece histopatolojik inceleme ile tanı konulmuştur (24). Sharma ve ark. (25) smear ve kültür üzerinde çok düşük oranda organizmalar bulmuştur (olguların \%3'ünden azında asite dirençli basiller pozitiftir ve vakaların \%20 'sinden azında pozitif kültür vardır). Bu çalışmada vakaların çoğunda histopatolojik bulgular ile tanı konulmuştur (\%93). Kazeifiye granülomatöz iltihabi hücre reaksiyonu tanısaldır (Resim 6- A, B). Po-

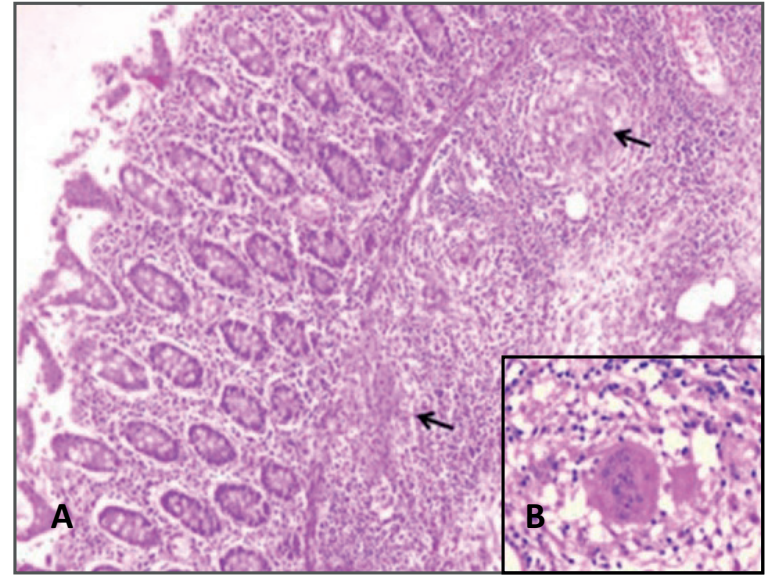

Resim 6. A- Tbc vakasında fokal kazeöz nekroz içeren epiteloid histiositlerden oluşan submukozal granülom formasyonu (HE x10). B- İç resim: Multinükleer histiositik dev hücrelerin izlendiği kazeifiye granülom (HE x40) (25).

limeraz zincir reaksiyonu (PCR), ekstra pulmoner tbc'un teşhisinde umut verici olarak ortaya çıkmasına rağmen, maliyet açısından uygun değildir (22).

\section{Segmenter müsküler distrofide histomorfoloji}

Barsağın segmenter müsküler defektlerinde spontanöz perforasyon oluşabilir. Perforasyon sayısı Tamai ve ark. (26)'larının 7 olgu içeren çalışmasında 6 vakada 1 perforasyon odağ 1,1 vakada ise 2 perforasyon odağ 1 saptanmıştır. Histolojik olarak perforasyon çevresinde segmental müskülaris propria defektleri saptanır. Erişkinlerde etiyoloji belirsizdir, fokal konjenital anomali neden olabilir (26). EhlersDanlos sendromu da tüm vücutta kollojen fiberleri etkileyen konjenital bir defekttir ve spontan perforasyon ve massif kanama gibi ciddi intestinal komplikasyonular ile karşımıza çıkabilir (12).

\section{KOLON PATOLOJILERINDE PERFORASYON}

\section{Kolon tümörlerine bağlı perforasyon}

Primer nedeni operasyon öncesi belirsiz, kolon tümörü ile ilişkili perforasyonun insidans oranı $\% 2,6$ ile \%10 arasındadır (27). Kolorektal kanserlerde (KRK), obstrüksiyon ve perforasyon, tek başına veya birlikte, neoplazmanın bulunduğu yerde veya proksimalde meydana gelebilir (13). Tümöre bağlı obstrüktif kolitin özellikleri şunlardır: (1) obstrüksiyon alanının ağız tarafında bulunan ülseroinflamatuvar bir lezyon; (2) obstrüksiyon alanının anal tarafı makroskopik ve histolojik olarak normaldir; ve (3) obstrüksiyon ile ülserasyon bölgeleri arasında normal mukoza mevcut ve sınır- 


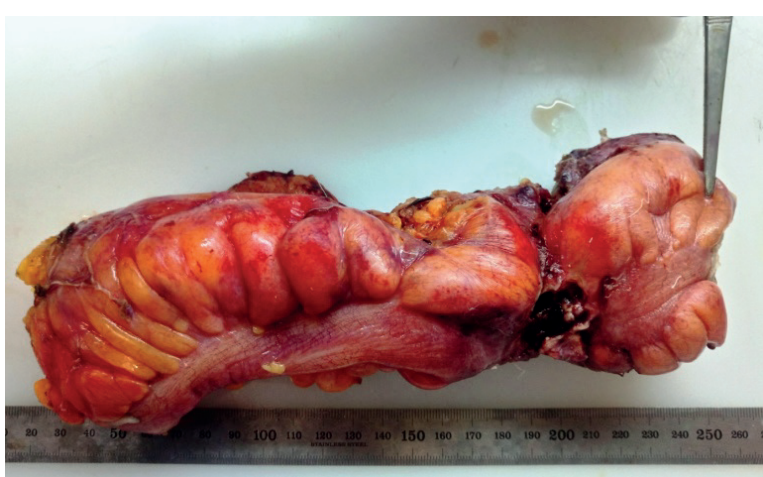

Resim 7. Rektal tümör vakasında serozal yüzde perforasyon alanı (Yılmaz Baş arşivi).

ları açıktır (28) (Resim 7,Yılmaz Baş Arşivi). Obstrüktif kolit vakalarında nadiren kolondan fulminan gangren gelişebilir ve histolojik olarak bu durum 'nekrotizan kolit' olarak adlandırılır (29).

\section{İskemik kolitte kolon perforasyonu}

Akut mezenterik iskemi (AMI), süperior mezenterik arter embolisi (\%50), tromboz ( $\leq \% 25)$ ve nadiren venöz tromboz nedenleri ile oluşan, yaşamı tehdit eden acil bir cerrahi durumdur, (13). Iqbal ve ark. (30) çalışmalarında, rektosigmoid bileşke ve sigmoid kolondaki (\%52) perforasyon oranları ise daha yüksek bulmuştur. Kolonun diğer yerlerinde perforasyon oranları sırasıyla \%17 (çekum), \%14 (çıkan kolon), \%7 (transvers kolon), \%8 (inen kolon) ve \%1 (rektum) olarak belirtilmiştir. Perforasyon boyutu 0,1$6,0 \mathrm{~cm}$ (ortalama $1,7 \mathrm{~cm}$ ) arasındadır (22). İskemik kolitte morfolojik olarak kolon mukozası ve duvarı kanamalıdır. İskemi süresine bağlı olarak mukozada yüzey epitelinde dökülme, erozyon, bazal membran hasarı, lamina propriada yoğun konjesyon, histolojik yapı kaybı ve iskemik nekroza bağlı ülser izlenebilir (31).

\section{Kemoterapötik ajanlara bağlı kolon perforasyonu}

İmatinib kaynaklı gastrointestinal perforasyon literatürde genellikle ilerlemiş gastrointestinal stromal tümörler (GIST) ile bağlantılı olarak nadiren bildirilmiștir, ancak literatürde en s1k görülen barsak perforasyon vakalarının, kolorektal karsinom, renal hücreli karsinom ve diğer solid malinitelerin tedavisinde kullanılan bevacizumab, sunitinib ve sorafenib ile ilişkili olduğu bildirilmiştir (32). Sorbitol ile Kayexalate'ın kombine kullanımı da intestinal nekroz veya perforasyona neden olabilmektedir. Histomorfolojik olarak kristaloidler perforasyon çevresinde tespit edilebilir (Resim 8) (33).

Sonuç olarak; perforasyon nedeni klinik ve histomorfolojik olarak belirsiz olan ve tanı güçlüğü

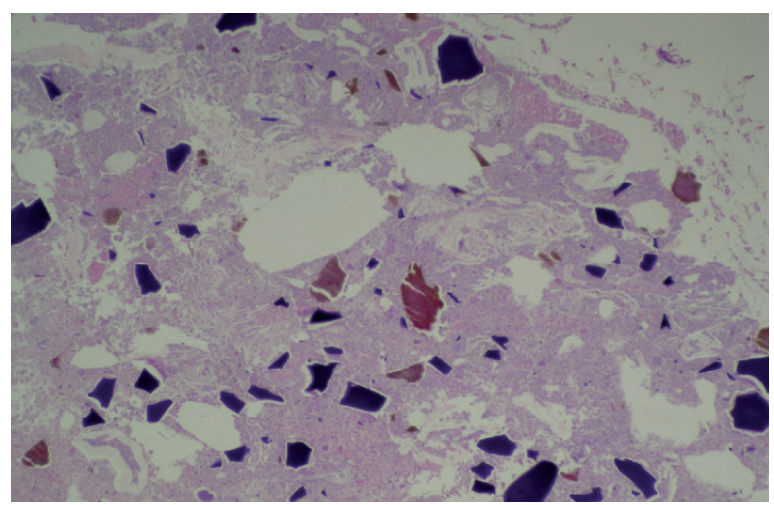

Resim 8. Perfore kolonda geniş, kavisli ve düzensiz aralıklı "fish scales" olarak gösterilen HE boyamada "violet kayexalate crystals" (33)

doğuran vakalar sınırlı olmakla birlikte karşımıza çıkabilmektedir. Bu tür nadir vakalarda cerrahi, patoloji, dermatoloji, romatoloji ve radyoloji gibi branşlar birbiriyle çok hızlı koordineli bir yaklaşım içine girmeli, tanı ve tedaviye yön vermelidir.

\section{MADDI DESTEK VE ÇIKAR iLIŞKisi}

Çalışmayı maddi olarak destekleyen kişi/kuruluş yoktur ve yazarların çıkara dayalı bir ilişkisi yoktur.

\section{KAYNAKLAR}

1. Gourgiotis S, Liakos N, Gemenetzis G, et al. Less commen nontraumatic bowel perforations: diagnosis and management through a retrospective study. Am Surg 2013; 79: 381-7.

2. Cohen MH, Reines JM. Spontaneous perforation of the ascending colon: Report of case and rewiew of the literature. Journal AOA 1976; 75: 596-601.

3. Ng DC, Kwok SY, Cheng Y, et al. Colonic amoebic abscess mimicking carcinoma of colon. Hong Kong Med J 2006; 12: 71-3.

4. Athie-Gutierrez C, Rodea-Rosas H, Guizar-Bermudez C, et al. Evolution of surgical treatment of amebiasisassociated colon perforation. J Gastrointest Surg 2010; 14: 82-7.

5. Peng QH, Wang $\mathrm{YF}, \mathrm{He} \mathrm{MQ}$, Zhang C, Tang Q. Clinical literature review of 1858 Crohn's disease cases requiring surgery in China. World J Gastroenterol 2015; 21: 4735-43.

6. Systemic vasculitis involving the gastrointestinal tract. Professor, Sections of surgical Pathology\&Gastroenterology University of Chicago Medical Center (test.pathologyportal.org/ site / 101st/pdf/companion16h04.pdf).

7. Karakaya K, Cömert M, Numanoğlu G. Multiple perforation along the transverse colon as a rare presentation of intestinal Behçet's disease: A case report. Clinics 2009; 64: 1231-3.

8. Singla K, Mahajan G, Agarwal S, Sharma S. Role of histopathological examination in nontraumatic perforation of colon. Trop Gastroenterol 2012; 33: 2659.

9. Diagnostic pathology of parasitic infections with clinical correlations, Second Ed., Yezid Gutierrez, 
Oxford University Press 2000; 150-2.

10. Weinrach DM, Wang KL. Amebic colitis in an asymptomatic patient. Arch Pathol Lab Med 2003; 127: 762.

11. Jones OP, Murphy JA, Hamid BN, et al. Colocutaneous fistula secondary of amoebiasis. Int J Surg Case Rep 2011; 2: 40-3

12. Rosai J., Surgical Pathology, Tenth edition, MOSBY Elsevier, 2011, Vol.1 pp741-6.

13. Doklestić SK, Bajec DD, Djukić RV, et al. Secondary peritonitis -evaluation of 204 cases and literature review. J Med Life 2014; 7: 132-8.

14. Sekmen Ü, Müftüoğlu T, Sağıroğlu J, Güngör Ö. Multiple perforation along the entire colon as a complication of intestinal Behçet's Disease: A rare case. The Saudi J Gastro 2008; 14: 85-7.

15. Fujiwara S, Shimizu I, Ishikawa M, et al. Intestinal Behçet's disease with esophageal ulcers and colonic longitudinal ulsers. World J Gastroenterol 2006; 12; 2622-4

16. Ustun S, Dagci H, Aksoy U, Guruz Y, Ersoz G. Prevalence of amebiasis in inflammatory bowel disease in Turkey. World J Gastroenterol 2003; 9: 18345.

17. Dowling CM, Hill ADK, Malone C, et al. Colonic perforation in Behçet's syndrome. World J Gastroenterol 2008; 14: 6578-80.

18. Baş Y. The histomorphology of colonic Behcet's disease. Gastroenterol Intest Syst 2017; 5: 1-6.

19. Kasahara $Y$, Tanaka $S$, Nishino $M$, et al. Intestinal involvement in Behçet's disease: review of 136 surgical cases in the Japanese literature. Dis Colon Rectum 1981; 24: 103-6.

20. Mitchell A, Dugas A, Collagenous colitis presenting as spontaneous perforation in an 80 year old woman: Report of a Case. BMC Gastroenterol 2016; 16: 124.

21. Freeman HJ. Long-term natural history and complications of collagenous colitis. Can J Gastroenterol 2012; 26: 627-30.

22. Awasthi S, Saxena M, Ahmad F, Kumar A, Dutta S. Abdominal Tuberculosis: A diagnostic dilemma. J Clin Diagn Res 2015; 9:1-3.

23. Lee MJ, Cresswell FV, John L, Davidson RN. Diagnosis and treatment strategies of tuberculous intestinal perforations: a case series. Eur J Gastroenterol Hepatol 2012; 24: 594-9.

24. Tandon HD, Prakash A. Pathology of intestinal tuberculosis and its distinction from Crohn's disease. Gut 1972; 13: 260-9.

25. Sharma MP, Bhatia V. Abdominal tuberculosis. Indian J Med Res 2004; 120: 305-15.

26. Tamai M, Satoh M, Tsujimoto A. Segmental muscular defects of intestine: a possible cause of spontaneous perforastion of the bowel in adults. Hum Pathol 2013; 44: 2643-50.

27. Eugene SA Yeo, Eu KW. Perforated colorectal cancer vs diverticular abscess, Letter to the Editor. Ann Acad Med Singapore 2011; 40: 375-8.

28. Glotzer DJ, Gpihl BG. Experimental obstructive colitis. Arch Surg 1966; 92: 1-8.

29. Killingback MJ, Williams KL. Necrotizing colitis. Br J Surg 1961; 49: 175-85.

30. Iqbal CW, Chun YS, Farley DR. Colonoscopic perforations: a retrospective review. J Gastrointest Surg 2005; 9: 1229-36.

31. Chiu CJ, McArdle AH, Brown R, Scott HJ, Gurd
FN. Intestinal mucosal lesion in low-flow states. I A morphologic, hemodynamic and and metabolic reappraisal. Arch. Surg 1970; 101: 478.

32. Jurdi NE, Bankoff M, Klein A, W. Saif MW. Perforation of the colon during imatinib mesylate (Gleevec) treatment in a patient with chronic myeloid leukemia (CML). Cureus 2016; 8: e660.DOI 10.7759/cureus.660.

33. Yamaguchi T, Ohyama S, Furukawa H, et al. Sigmoid colon diverticula perforation associated with sevelamer hydrochloride administration: A case report. Annals Med Surg 2016; 10: 57-60. 